\title{
Biochemical Estimation of Glucose 6 Phosphate Dehydrogenase Deficiency in Saudi Adults: Different Methods and Its Rationalization
}

\author{
Jummanah Jarullah ${ }^{*}$, Soad AlJaouni', Mahesh C. Sharma², Bushra M. S. Jarullah ${ }^{2}$ \\ ${ }^{1}$ Haematology Research La, King Fahd Medical Research Centre, King Abdulaziz University, Jeddah, KSA \\ ${ }^{2}$ Department of Biotechnology, Kadi Sarva Vishwavidyalaya, Ghandinagar, India \\ Email: jumanaj@yahoo.com
}

Received 31 January 2014; revised 6 March 2014; accepted 20 March 2014

Copyright @ 2014 by authors and Scientific Research Publishing Inc.

This work is licensed under the Creative Commons Attribution International License (CC BY).

http://creativecommons.org/licenses/by/4.0/

(c) (i) Open Access

\section{Abstract}

Background: Glucose-6-phosphate dehydrogenase (G6PD) deficiency is the most common human enzymopathy affecting 400 million people, globally. G6PD deficiency is an X-linked genetic condition, which is more likely to affect males than females. Heterozygous females go undetected in a commonly used method. The aim of the study was to identify \& rationalize different biochemical methods for detections of G6PD deficiency. Methods: Cross section retrospective study was conducted on 1584 (800 males, 784 females) blood samples collected from King Abdulaziz University Hospital (KAUH) and King Fahd Armed force hospital (KFAFH) in Jeddah, Western Saudi Arabia. Blood samples were screened for G6PD activity by fluorescence spot test, semi quantitative color reduction test and spectrometric quantitative evaluation. Hemoglobin $(\mathrm{Hb})$ was measured on the same sample by BC-3200 Auto hematology Analyser. G6PD activity was recorded as U/g Hb. Samples identified as deficient with cutoff $\leq 4.6 \mathrm{U} / \mathrm{gHb}$. Results: The prevalence of G6PD deficiency identified by fluorescence spot test was $73(4.6 \%)$ and all were deficient male. By semi quantitative method, the prevalence rate was $51(3.2 \%)$ and again all were male deficit patients. However, when quantitative spectrometric method was used, the prevalence was found in $90(5.7 \%)$, where in $73(4.6 \%)$ deficient patients were males and $17(1.1 \%)$ were females. Conclusion: Since the fluorescence spot test did not miss any G6PD deficient male, it should be restricted to males and quantitative test should be done on females. Each ethnic group should cultivate their own cutoff value for categorization of deficient patients.

${ }^{*}$ Corresponding author.

How to cite this paper: Jarullah, J., et al. (2014) Biochemical Estimation of Glucose 6 Phosphate Dehydrogenase Deficiency in Saudi Adults: Different Methods and Its Rationalization. Advances in Bioscience and Biotechnology, 5, 434-437. 


\section{Keywords}

\section{Glucose 6 Phosphate Dehydrogenase; Fluorescence; Semi-Quantitative \& Quantitative}

\section{Introduction}

G6PD deficiency is a most common hereditary erythroenzymopathy, present in approximately 400 million people throughout the world [1]-[3]. Since G6PD deficiency is an X-linked condition; males are either G6PD normal or G6PD deficient hemizygotes, whereas females are G6PD normal homozygotes, deficient homozygotes, or heterozygotes. X chromosome inactivation is frequently nonrandom; varying proportions of red blood cells may have either G6PD normal or deficient. As a result, female heterozygotes will have a continuum of G6PD activity results. Various biochemical testing methods are used to identify deficient patients. Early recognition of G6PD deficiency can help prevent serious complications. In the Kingdom of Saudi Arabia (KSA), cumulative data for G6PD deficiency are relatively high, ranging from 1.9\% to 18\% [4]-[6]. Early recognition of G6PD deficiency can help to prevent serious complications. Our aim in this study is to identify G6PD deficient adult patients by using all the available biochemical methods and justify their use. Cytochemical and molecular typing is an alternative choice. In view of the fact that molecular typing is cost effective and cytochemical method is time consuming, biochemical methodology is most attractive choice. Biochemical approach will be more rational especially in the developing world, where G6PD deficiency is more common.

\section{Methods}

Cross section retrospective study was conducted to determine the prevalence of G6PD deficiency at King Abdulaziz University Hospital (KAUH) and King Fahd Armed force hospital (KFAFH) in Jeddah, Western Saudi Arabia. Consent was obtained from the participants prior to conducting the research. The study was approved by the Biomedical Ethical Research Committee of the Faculty of Medicine of King Abdulaziz University (Reference No. 530-11).

Qualitative fluorescence spot test (FST) was done on 1584 (800 males, 784 females) with cutoff point of 2.1 Units/gram Hemoglobin (U/g Hb) [7] Semi quantitative and qualitative biochemical tests were done on the same cohort. The semi quantitative color reduction test was used to detect the color change from blue to colorless using blue dye, dichlorophenol indophenol, by NADPH.(Procedure no. 400 from Sigma Diagnostics, St. Louis, MO) [8]. For quantitative estimation, commercial sigma kit ((No. 345-UV).) was used to measure spectroscopic absorbance at $340 \mathrm{~nm}$ in kinetic mode described by Beutler et al. [9]. The amount of NADPH produced is an index of G6PD activity over a set period of time at $37^{\circ} \mathrm{C}$. Hemoglobin $(\mathrm{Hb})$ was measured on the same sample by BC-3200 Auto hematology Analyzer. G6PD activity was recorded as U/g Hb. The cut off value for quantitative G6PD deficiency was $\leq 4.6 \mathrm{U} / \mathrm{g} \mathrm{Hb}$. The entire tests were performed within 24 hours of collection of samples. DNA was extracted from the all the deficient samples and stored at $70^{\circ} \mathrm{C}$ for molecular typing. Analysis of frequency distribution of G6PD values were performed using SPSS version 16.

\section{Results}

The prevalence of G6PD deficiency identified by fluorescence spot test was 73(4.6\%) deficient male. By semi quantitative method the prevalence rate was 51(3.2\%) and again all were male deficit patients. However, when quantitative method was used the prevalence was found in 90(5.7\%), where in 73(4.6\%) deficient patients were males and 17(1.1\%) were females Table 1.

\section{Discussion}

G6PD deficiency has been the subject of number of studies in the recent past. There is a growing awareness that robust and reliable G6PD test are required for the early detection of G6PD deficiency. WHO has also endorsed screening blood samples from neonates in population with prevalence of G6PD of 3\% - 5\% or more in males [3]. Adult G6PD deficient cohort is at the risk of medical emergency, due to emerging of new drugs at high rate. Saudi Arabia is one those country in which the G6PD prevalence is high and awareness is mandatory [4] [5] [8] 
Table 1. Glucose 6 phosphate dehydrogenase deficiency in Saudi adults.

\begin{tabular}{ccccc}
\hline Gender Total 1584 (800M;784F) & Frequency & Male & Female & Cut Out Value \\
\hline Fluorescence Spot Test & $73(4.6 \%)$ & $73(4.6 \%)$ & nil & $\leq 2.1 \mathrm{U} / \mathrm{gHb}$ \\
Semi Quantitive Color Test & $51(3.2 \%)$ & $51(3.2 \%)$ & nil & $\leq 2.1 \mathrm{U} / \mathrm{gHb}$ \\
Quantitative Spectrophotomer Method $^{*}$ & $90(5.6 \%)$ & $73(4.6 \%)$ & $17(1 \%)$ & $\leq 4.6 \mathrm{U} / \mathrm{gHb}$ \\
\hline
\end{tabular}

* Statistic was done using SPSS 16.

[10]. In the view of the high prevalence rate in this country, the present study was taken up to evaluate the most convenient method for the detection of G6PD deficiency. Number of studies has promoted the use of fluorescent spot test as a screening method for G6PD deficiency [11]. Present study shows similar results, however we advocate the use of fluorescence spot test to be restricted to only male cohort only. The fluorescent spot test is considered reliable for the detection of hemizygous males but is unreliable for the detection of heterozygous females. The population of healthy erythrocytes in heterozygous females (on average 50\% of the erythrocytes) converts enough $\mathrm{NADP}^{+}$into NADPH to produce fluorescent spots, missing out on heterozygous females. To detect female G6PD heterozygous deficient patients quantitative test or molecular typing is needed. The overall frequency of G6PD deficiency using fluorescence spot test was found in 73(4.6\%) all of which were deficient males. However when quantitative method was used the prevalence was found to be $90(5.6 \%)$, where in $4.6 \%$ deficient patients were males and $1 \%$ were females. Similar finding were reported by Reclose et al. [12]. We established that fluorescent spot test did not miss any deficient males. Results for detection of deficient male by quantitative spectrophotometer method were comparable to fluorescence spot test. Semi quantitative color test missed few adult deficient male and all deficient females. Three methods have biochemical approach, and till date, there is no reliable biochemical assay to detect G6PD heterozygotes. DNA mutation analysis may provide supplementary approach. To use DNA-based screening for specific ethnic groups, common G6PD mutations specifically present in that group or geographic area should be analyzed. The advantages of DNA analysis include the ability to identify female heterozygotes. Nevertheless, all female heterozygotes may not necessarily have G6PD deficient genotype belonging to the ethnic group. Those G6PD deficient male and female, having sporadic mutation, which is not included in a particular mutation screening panel, may be missed, whereas by a simple biochemical screening test almost all males and some female can be detected [13] [14] Further, DNAbased screening may require additional equipment and trained laboratory personnel [15] [16]. Third world countries were G6PD is more prevalent, cost of molecular method is not feasible. Hence we strongly recommend fluorescence spot test for screening G6PD males and quantitative spectroscopic method for screening females. However, a combination of biochemical methodologies, supplemented with common G6PD mutations analysis will enhance the identification heterozygous females [17].

\section{Conclusion}

Fluorescence spot test does not miss any G6PD deficient male; therefore, it should be restricted to males however for the identification of G6PD deficiency in females; fully quantitative method is suitable. To overcome uncertainties associated with variable enzyme activity cut-offs and to identify female heterozygote misclassified as G6PD normal, more investigation is needed. This is a major challenge, an unresolved question as to which level of enzyme activity encompass no risk for sever haemolysis. Each ethnic group or geographical area should work on their own cut off points with the help of molecular typing, biochemical method and cytochemical confirmation, simultaneously.

\section{References}

[1] Frank, J.E. (2005) Diagnosis and Management of G6pd Deficiency. American Family Physician, 72, 1277-1282.

[2] Luzzatto, L., Vulliamy, T.J. and Mehta, A. (2001) Glucose 6-Phosphate Dehydrogenase Deficiency. In: Valle, D., Scriver and Beaudet, A.L., The Metabolic and Molecular Bases of Inherited Disease, Sly D, New York, 4517-4534.

[3] World Health Organization (1989) Worldwide Prevalence of G6PD Deficiency According to the World Health Organization with Permission. The Bulletin of the World Health Organization, 67, 601-611. 
[4] Ali, A.K. (1996) Common G6PD Variant from Saudi Population and Its Prevalence. Annals of Saudi Medicine, 16, 654-656.

[5] Nasserullah, Z., Al Jame, A., Abu Srair, H., Al Qatari, G., Al Naim, S. and Al Aqib, A. (1998) Neonatal Screening for Sickle Cell Disease, Glucose-6-Phosphate Dehydrogenase Deficiency and a-Thalassemia in Qatif and Al Hasa. Annals of Saudi Medicine, 118, 289-292.

[6] Al-Awamy, B.H., Al-Muzan, M., Al-Turki, M. and Serjeant, G.R. (1984) Neonatal Screening for Sickle Cell Disease in the Eastern Province of Saudi Arabia. Transactions of the Royal Society of Tropical Medicine \& Hygiene, 78, 792794.

[7] Tan, I.K. and Whitehead, T.P. (1969) Automated Fluorometric Determination of Glucose-6-Phosphate Dehydrogenase (G6pd) and 6-Phosphogluconate Dehydrogenase (6pgd) Activities In Red Blood Cells. Clinical Chemistry, 15, 467478.

[8] Al-Jaouni, S.K., Jarullah, J., Azhar, E. and Moradkhani, K. (2011) Molecular Characterization of Glucose-6-Phosphate Dehydrogenase Deficiency in Jeddah, Kingdom of Saudi Arabia. BMC Research Notes, 4, 436. http://dx.doi.org/10.1186/1756-0500-4-436

[9] Beutler, E., Blume, K.G., Kaplan, C., Lohr, W., Ramot, B. and Valetinine, W.N. (1979) International Committee for Standardization in Hematology Recommended Screening Test for Glucose-6-Phosphate Dehydrogenase. British Journal of Haematology, 43, 469-477.

[10] Jarullah, J, Soad, A.J., Sharma, M., Bushra, M. and Mohammad, A.K. (2012) Detection of Glucose-6-Phosphate Dehydrogenase Deficiency in Heterozygous Saudi Female Neonates. Enzyme Engineering, 1, 2-4.

[11] Duangdao, N., Rick, P., Attakorn, P., Nicholas, P., Nicholas, J.W. and Mallika, I. (2013) Evaluation of the Phenotypic Test and Genetic Analysis in the Detection of Glucose-6-Phosphate Dehydrogenase Deficiency. Malaria Journal, 12, 289.

[12] Reclos, G.J, Hatzidakis, C.J. and Schulpis, K.H. (2000) Glucose-6-Phosphate Dehydrogenase Deficiency Neonatal Screening: Preliminary Evidence That a High Percentage of Partially Deficient Female Neonates Are Missed During Routine Screening. Journal of Medical Screening, 7, 46-51. http://dx.doi.org/10.1136/jms.7.1.46

[13] Kaplan, M. and Hammerman, C. (2011) Neonatal Screening for Glucose-6-Phosphate Dehydrogenase Deficiency: Biochemical versus Genetic Technologies. Seminars in Perinatology, 35, 155-161. http://dx.doi.org/10.1053/j.semperi.2011.02.010

[14] Wang, F.L., Boo, N.Y. and Ainoon, O. (2009) Comparison of Detection of Glucose-6-Phosphate Dehydrogenase Deficiency Using Fluorescent Spot Test, Enzyme Assay and Molecular Method for Prediction of Severe Neonatal Hyperbilirubinaemia. Singapore Medical Journal, 50, 62-67.

[15] Minucci, A., Giardina, B. and Zuppi, C. (2009) Glucose-6-Phosphate Dehydrogenase Laboratory Assay: How, When, and Why? IUBMB Life, 61, 27-34. http://dx.doi.org/10.1002/iub.137

[16] Zaffanello, M, Rugolotto, S. and Zamboni, G. (2004) Neonatal Screening for Glucose-6-Phosphate Dehydrogenase Deficiency Fails to Detect Heterozygote Females. European Journal of Epidemiology, 19, 255-257. http://dx.doi.org/10.1023/B:EJEP.0000020445.48298.3f

[17] Lin, Z., Fontaine, J.M. and Freer, D.E. (2005) Alternative DNA-Based Newborn Screening for Glucose-6-Phosphate Dehydrogenase Deficiency. Molecular Genetics and Metabolism, 86, 212-219. http://dx.doi.org/10.1016/j.ymgme.2005.05.008 